\title{
Study of Sign in Nonverbal Communication
}

\author{
Gaimei Zhao \\ Xi'an Peihua University, Xi'an 710125, China. \\ 1142626982@qq.com
}

Keywords: sign; nonverbal communication.

\begin{abstract}
Due to the rapid development of science and technology, people's way of life has changed a lot. Now they prefer to use a more efficient and convenient way in daily interactions so to meet the quick pace a modern society demands. Among them, the frequent usage of signs as means in people's way of communication, such as pictures in public places, emoticon in internet play more and more significant role in people's way of communication. Based on the knowledge of nonverbal communication, this paper intends on discovering the unique function of signs in communication so as to enrich the research of nonverbal communication in this field.
\end{abstract}

\section{Introduction}

In daily interaction, we communicate both verbally and nonverbally, though most people are hardly aware of nonverbal communication and do not realize its potential. Though the linguists have now paid much more attention to the researches of nonverbal communication, their interests are mainly focused on the studies of gestures, postures and facial expression as ways of nonverbal communication.

It is easily noticed that, due to the rapid development of science and technology, people's way of life has changed a lot. Now they prefer to use a more efficient and convenient way in daily interactions so to meet the quick pace a modern society demands. Among them, the frequent usage of signs as means in people's way of communication, such as pictures in public places, emoticon in internet play more and more significant role in people's way of communication.

Based on the knowledge of nonverbal communication, this paper intends on discovering the unique function of signs in communication by giving the analysis to the aspects above mentioned so as to enrich the research of nonverbal communication in this field.

\section{Literature Review}

\subsection{Communication.}

Communication is the basis of all human contact, but it's difficult to find a single definition due to its complexity. In its most general sense, communication refers to the process by which we develop, share or exchange our meaning, information, ideas, feelings and so on. Put simply, it means getting across our ideas, view, feelings, emotions, etc.

For the message we want to convey, we can choose the means both verbally and nonverbally. The linguists proposed that a full, unhindered, natural communication is composed of the inseparable unit of verbal and nonverbal communication.

\subsection{Verbal Communication and Its Limitation.}

Verbal communication refers to the communication done both in oral and written language. Because of the important role of language in reaching out to make contact with others, verbal communication is traditionally assumed as the most efficient coding system in human interaction. Thus communication is simplified as merely consisting of lexical-morphological-syntactical complex for a long history.

However, by blindly admitting this unquestionable truth, verbal language still appears to have some limited aspects in the light of a finer analysis of our communicative activities. In certain circumstances, when our communication is blocked from the verbal modality by sensory incapacity, 
by environmental obstruction, or by speech taboo, etc. the nonverbal modality frequently assumes the functional burdens of speech. So we say verbal language is not always omnipotent.

\subsection{Nonverbal Communication.}

\subsubsection{Definition of Nonverbal Communication.}

Different scholars have made different efforts to define nonverbal communication. Here we incline to offer Samovar and Porter's one as "nonverbal communication involves all those nonverbal stimuli in a communication setting that are generated by both the source and his or her use of the environment and that have potential message value for the source or receiver". [1] This definition not only marks the boundaries of nonverbal communication but also reflects how the process actually works.

\subsubsection{Taxonomies of Nonverbal Communication.}

Most classifications divide nonverbal messages into two comprehensive categories: those that are primarily produced by the body (appearance, movement, facial expressions, eye contact, touch, smell, and paralanguage); and those that the individual combines with the setting (space, time, and silence).

\section{Signs in Nonverbal Communication}

\subsection{The Sign Theory.}

In Saussure's view, language is a system of signs, each of which consists of two parts: signified (concept) and signifier (sound image). Although its users treat the signifier as standing for the signified, Saussurean semioticians emphasizes that there is no necessary, intrinsic, direct or inevitable relationship between the signifier and the signified. Therefore, the linguist cannot attempt to explain individual signs in a piecemeal fashion. In the context of natural language, Saussure stressed that there is no inherent connection between the signifier and the signified, that is, between the sound or shape of a word and the concept to which it refers. [1] The relation between a signifier and its signified is not a matter of individual choice. If it were then communication would become impossible. The individual has no power to alter a sign in any respect once it has become established in the linguistic community.

\subsection{Resemblance between the Sign and Its Object.}

In daily life, there are many cases that the sign and its object have the quite resemblance. A sign is an icon insofar as it is like that thing and used as a sign of it. Pictures resemble what they represent only in some respects. What we tend to recognize in an image are analogous relations of parts to a whole. Even the most realistic image is not a replica or even a copy of what is depicted. We rarely mistake a representation for what it represents.

Beyond any conscious intention, we communicate through gesture, posture, facial expression, intonation and so on. Analogical codes unavoidably give us away, revealing such things as our moods, attitudes, intentions and truthfulness. Every sign has some kind of material embodiment, whether in sound, physical mass, color, movements of the body, or the like.

\section{Pictures in Nonverbal Communication}

\subsection{Pictures in the Early Education.}

All children have the right to express what they want and how they feel. But this is not always easy to do. Before children speak, they have the attention to communicate with others. When the adults show the colorful pictures many times, the baby may choose the picture you showed them before. Sometimes they may act some movements. For example, when the baby find the grape, he may act just like eating it, peeling the grape, putting it into the mouth, sucking it, throwing away the seeds. Each time, he may do it when he finds the grape picture.

The pictures used at this stage may be photographs, colored or black and white line drawings, or even tangible symbols. [2] 


\subsection{Pictures in Public Places.}

In public places there are many pictures to give us necessary directions, especially the advertisement and some pictures of traffic.

\subsubsection{Traffic Pictures.}

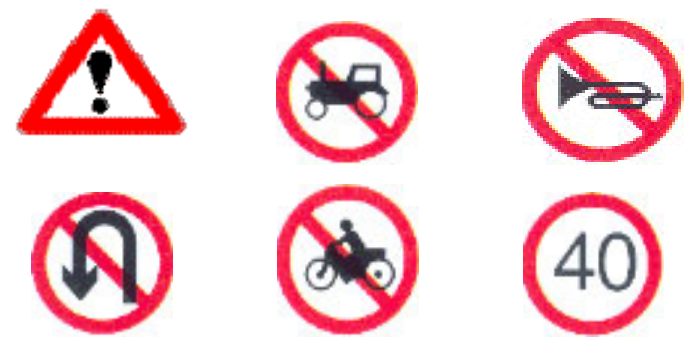

Fig. 1 Traffic pictures.

When we look at the traffic pictures on the road, these signs may give us the potential concept, our action will be changed. From the first, we know the meaning of being careful; the truck is not allowed to pass; pressing the horn is forbidden; turning around here is not allowed, the motor is not permitted, the car can be parked here, the limitation of the car is $40 \mathrm{~km}$. The car cannot be parked here.

On the road, when the sidewalks find the pictures, the resembling may make them low the speed and pass safely. If there is no traffic sign on the road to say something, danger will be ahead. From above we know many of these pictures are iconic signs resembling the objects and actions to which they refer either directly or metaphorically.

\subsubsection{Advertisement.}

Over time, picture became more symbolic and less iconic. This is the sign of Shanghai Bicycle Factory. On the upper is the picture of a bicycle made of two characters "the forever" and the lower part is the English word "the forever". The picture means that the bike of this band is good in quality. [3]

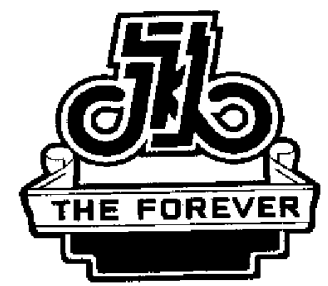

Fig. 2 "the forever"

From above, we know that pictures play a considerable part in nonverbal communication and it should have its position in our classification of nonverbal communication. The picture makes the communication more succinct, definite and convenient. Much of the conversational implication is fully expressed by the picture. As one example in sign system, the picture with words make a satisfying communication in public places and in the sea of increasing advertisement industry. With the further study, the sign theory shows its great influence in our life and enrich the study of nonverbal communication.

\section{Emoticon in Internet}

\subsection{Introduction of CMC.}

After the invention of the Internet, computers and the Internet are more and more used in every aspect of social life. As a media of communication, CMC (computer mediated communication), especially e-mails and those instant-messaging and chat software, provides people another channel of communication. Such software includes Tencent QQ, MSN Messenger, ICQ, Yahoo Messenger, AOL Messenger, etc.

The studies and researches about nonverbal aspect of CMC have been mainly from the perspective of the study of communication, psychology, and socio-psychology. There is a lack of such studies from the perspective of linguistics. Further, newly developed software also provides new means to 
facilitate nonverbal communication, such as providing more emoticons. Based on the existing theories about nonverbal communication, we probed the nonverbal communication in CMC, analyzed several examples, and derived a conclusion about the function and realization of nonverbal communication in CMC. [4]

\subsection{The Nature of CMC.}

Decided by the nature of computers and the Internet, CMC is distinguished from other means of communications in several ways. The most noticeable characteristic of CMC is that people tend to be at different locations when carrying out a CMC. With the Internet, a Chinese citizen could conveniently chat with an American. Secondly, texts are the main form of the messages for CMC. This is different from telecommunication, in which people's voices carry the message. Further, CMC could be aided by multimedia means, such as pictures and sounds. [5]

\subsection{Emoticons in CMC.}

Emoticons in CMC have several functions. They could be used to show people's emotion, to greet each other, to make the conversation more vivid, to simplify the typing, and to avoid misunderstanding. Just like facial expressions and body languages, emoticons could to some extent be seen as the imitation of facial expressions and body languages in the Internet environment. However, as a different code system, emoticons have their characteristics. The functions of emoticons are discussed respectively as follows:

Emoticons are used to show people's emotion. In FTF communication, people could show their emotions by their facial expressions. However, since people cannot see each other in many cases of CMC, emoticons could help them to show their emotions.

a) To greet each other

Just as a smile could be some kind of greeting, people use emoticons to greet each other on the Internet.

Example:

A: 9 .

B: hi!

Here, A greets B by send a “ 9 )" to B.

A communication is completed between $\mathrm{A}$ and $\mathrm{B}$, resembling two people saying hello to each other on the street and go on their own business. [6]

b) To make the conversation more vivid.

c) To simplify the typing.

d) To avoid misunderstanding.

\section{Conclusion}

As stated in part one, this paper is to focus on the urgent need of understanding that a full, natural communication is composed of the inseparable unit of verbal and nonverbal communication. Nonverbal communication is an important component of communication. Verbally, it is described as the opposition of verbal communication, namely the communication that is not based on words, such as facial expressions, body language, or gestures. Nonverbal communication plays an important role in the process of communication.

This paper pays more attention to the content and kinds of nonverbal communication. The realization of nonverbal communication includes not only the facial expressions, eye contacts, tones, clothing, body languages, gestures, etc. which are studied more in the former time. To the functions of sign in communication, we make a further study especially about pictures and emoticon.

The pictures and emoticon play the various function in nonverbal communication. First, these signs in our life reinforce the verbal communication and make us get a good understanding. Second, the signs are the channel to indicate the meaning of one's saying, such as in public places to give us a direction and in private space to convey more implied meaning. 
The writer's future study is to use the sign theory to explain the phenomenon such as pictures and emoticon with few words making deeper impression on the communicators. Thus the writer is to explore the further close relationship between the verbal communication and nonverbal communication to prove that only the combination of verbal and nonverbal communication is the desirable channel to get a clear and definite understanding in communication.

\section{References}

[1]. Hu Zhuanglin. Linguistics: A course book. Peiking University Press, 2001.

[2]. Liu Ning, Liu Junli. Communicational Function of Graphics and Its Application in English Teaching. Journal of Beijing Institute of Technology (Social Science Edition). 2003. p. 22-24.

[3]. Li Shaofeng, Wanghong. Non verbal communication and its Semiotics. Journal of Handan Teachers College. 1997. P 36-38.

[4]. Information on:http://www.iidc.indiana.edu

[5]. Information on:http://www.wjsgjzx.com.cn

[6]. Information on:http://www.aber.ac.uk 